\title{
OPHTHALMOLOGY IN LECTURES OF A CENTURY AGO
}

BY

\author{
R. R. JAMES \\ WOODBRIDGE
}

ABOUT 115 years ago a volume of lectures was published on anatomy, surgery, pathology, including observations on the nature and treatment of local diseases which were delivered at St. Bartholomew's Hospital, by Abernethy. A few ophthalmic extracts of a century ago may be of interest.

As a lecturer, Abernethy's style was distinctly colloquial. He believed in repetition and was a great narrator of case histories bearing on the various diseases. He must have known how to keep the students interested and the fact that emphasis by reiteration was an important means of helping his audience to appreciate the essentials.

He gives a very short section on elementary optics, but his main thesis in ophthalmology is in operative surgery. Here and there in the body of the work are some case histories which have an ophthalmological bearing. For instance, under sarcomatous tumours, and he uses the term sarcomatous, not in the modern malignant sense, but as indicating fleshy tumours, he relates the experience of a Russian doctor, travelling in Italy, who met a man with a large tumour hanging over the side of his face. It was seven inches in length with a circumference of $3 \frac{1}{2}$ inches. It had been forming several years and he induced the man to let him remove it. $\mathrm{He}$ found that it grew beneath the conjunctiva of the lower part of the globe and lower lid and protruded between the lids. After cutting carefully through the conjunctiva he removed it and much to his surprise, the cornea, even where it had been covered by the tumour, remained transparent.

In dealing with the treatment of ulcers he calls attention to the possibility of belladonna poisoning following local application. Under a short section on delusions of sight he tells a story of an accident to himself when riding. The horse threw up. his head and Abernethy received a pretty severe blow on the nose.

On reaching a stable near at hand he washed his face and squeezed the nasal bones into their proper place as well as he could. "The people were certainly very kind, and wished to send for a surgeon to me; but I told them I would rather they sent for a hackney coach, which they did, and I went home in it." He then perceived an imperfection in his sight. This was indistinct, from the eclipse of the third of every object on the right side. "If I saw a long 
name as my own, for instance, $A$-ber-ne-thy, in a bookseller's shop window, or any such place, I could see $A$-ber-knee, but I could not see the thigh at all." He tried each eye separately as well as the two together and found no change. He refers to Wollaston's views on similar cases. Discussing this experience with a medical friend, Abernethy said that he regretted that when he was in this state he had not squinted, to have seen how the things would have looked then. "But since that time I have been entertained with it often, and often without having any blow; and I have on these occasions squinted too, and it's just the same. And let those account for it as arising from a decussation of the nerve, do it; My own opinion is, that it arises, from the irregular actions of the retina." In parenthesis, a case is told of a man who got scotomata after taking a cup of tea or coffee. "As he got better, and less nervous, he has only seen the arms or legs of persons, without seeing any other part of them." Headache is not mentioned in connexion with this case, but it reads like one of migraine.

In the section on operative surgery Abernethy deals mainly with cataract. He demands mobility of the iris, before deciding to operate ; in other words he fights shy of synechiae as evidence of past inflammation. And he insists on the presence of perception of light. "I should choose a person who could see the transit of a candle through the room, or tell me where the windows were."

He describes the operation of couching and incidentally ascribes it to Celsus and says that the term is one he should like to see expunged from the surgical dictionary.

"Of late, Mr. Hey, of Leeds" has advised the operation of posterior needling. He seems to have coupled it with reclination. Mr. Saunders brought the same operation into practice, performed from the front of the eye; but he was particularly induced to do it on children who have been born with cataract.

"Extraction of the lens is a very difficult operation, very difficult." Abernethy extols Mr. Phipps as an operator. He used a broad knife (which was almost certainly Beer's knife), but did not complete the whole corneal section with it. He left a little filament of cornea below which he divided with another little knife, with which he seems to have opened the capsule of the lens as well. Pressure then delivered the lens: " it will jump out into a bottle."

The only other subject mentioned in this section is mucocele and lacrymal fistula. He describes Blizard's method of treatment by filling the sac with quicksilver, mentions syringing and the insertion of styles. And as a matter of course he places, in every word he utters almost, very strong emphasis on the need for attending to the general health and the state of the bowels. 